\title{
BIOINFORMATION
}

Discovery at the interface of physical and biological science.

\section{From sequence analysis of DPP-4 to molecular docking based searching of its inhibitors}

\author{
Awad Saeed Alsamghan ${ }^{1}$, Afaf S. Alwabli2 ${ }^{*}$, Mohammed Abadi ${ }^{3}$, Safar A. Alsaleem ${ }^{4}$ Dalia \\ Mohammed Anbari ${ }^{5}$, Amani Saleh Alomari ${ }^{6}$, Othman Alzahrani ${ }^{7 \& 8}$ Qamre Alam ${ }^{9}$ \& Mohammed \\ Tarique $\mathbf{1 0}^{*}$
}

${ }^{1}$ Department of Family and Community Medicine, College of Medicine, King Khalid University, Abha, KSA-61421; ${ }^{2}$ Department of Biological Sciences, Faculty of Science, King Abdulaziz University, Jeddah 21589, Kingdom of Saudi Arabia; ${ }^{3 \& 4}$ Department of Family and Community Medicine, College of Medicine, King Khalid University, Abha, KSA-61421.5\&6Department of Biochemistry, Faculty of Science, King Abdulaziz University, Jeddah 21589, Kingdom of Saudi Arabia; 7Department of Biology, Faculty of Sciences, University of Tabuk, Tabuk 71491, Kingdom of Saudi Arabia; ${ }^{8}$ Genome and Biotechnology Unit, University of Tabuk, Tabuk 71491, Kingdom of Saudi Arabia; ${ }^{9}$ Medical Genomics Research Department, King Abdullah International Medical Research Center, King Saud bin Abdulaziz University for Health Sciences, Ministry of National Guard Health Affairs, Riyadh, Kingdom of Saudi Arabia; ${ }^{10}$ Center for Interdisciplinary Research in Basic Sciences, Jamia Millia Islamia, Jamia Nagar, New Delhi-110025, India. Dr. Afaf S. Alwabli- Email: afafalwabli@yahoo.com; Dr. Mohammed Tarique - E-mail id: tariqueaiims@gmail.com; *Corresponding author with equal contribution

Author contacts:

Awad Saeed Alsamghan - E-mail: dr.awadsaeed1@gmail.com; Afaf S. Alwabli - E-mail: afafalwabli@yahoo.com; Mohammed Abadi - Email:mabade@kku.edu.sa; Safar A. Alsaleem - Email:safar10abadi@hotmail.com; Dalia Mohammed Anbari - E-mail: danbari@stu.kau.edu.sa; Amani Saleh Alomari-E-mail: aalomari0027@stu.kau.edu.sa; Othman Alzahrani-E-mail: o-alzahrani@ut.edu.sa; Qamre Alam-E-mail: alamqa@ngha.med.sa; Mohammed Tarique - E-mail: tariqueaiims@gmail.com Submitted by Dr. Mohammad Tarique, Center for Interdisciplinary Research in Basic Sciences, Jamia Millia Islamia, Jamia Nagar, New Delhi-110025, India; E-mail id: tariqueaiims@gmail.com

Received March 3, 2020; Revised April 19, 2020; Accepted May 7, 2020; Published June 30, 2020

DOI: $10.6026 / 97320630016444$

Declaration on official E-mail:

The corresponding author declares that official e-mail from their institution is not available for all authors

Declaration on Publication Ethics:

The authors state that they adhere with COPE guidelines on publishing ethics as described elsewhere at https://publicationethics.org/. The authors also undertake that they are not associated with any other third party (governmental or non-governmental agencies) linking with any form of unethical issues connecting to this publication. The authors also declare that they are not withholding any information that is misleading to the publisher in regard to this article. 


\section{BIOINFORMATION \\ Discovery at the interface of physical and biological sciences}

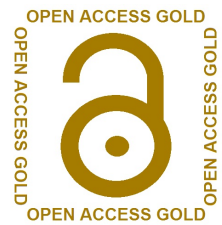

Abstract:

Literature data suggests that Dipeptidyl peptidase-4 (DPP-4) is a potential target for type 2 Diabetes Mellitus. Therefore, it is of interest to identify new DPP-4 inhibitors using molecular docking analysis. We document compounds such as STOCK1N-98884, STOCK1N-98881, and STOCK1N-98866 with optimal binding features with DPP-4 from the ligand database at https://www.ibscreen.com/ for further consideration.

Keyword: DPP-4, GLP-1, diabetes, docking analysis, inhibitor

\section{Background:}

Insulin resistance in type 2 diabetes and related issues are known [1]. Symptoms associated with the disease include retinopathy, edema, micro aneurysms, nephropathy outlines, symmetrical fringe neuropathy influencing engine and tactile nerves of the smaller attachments [2-4]. Several models of treatments using insulin, secretagogues (sulfonylureas and incretins) and hypoglycemias (biguanides, thiazolidinediones and a-glucosidase inhibitors) are currently available [5-10]. Inhibitors of the dipeptidyl peptidase-4 (DPP-4) are linked with the activities of GLP-1 and gastric inhibitory polypeptide (GIP) [7, 8]. Description of the structural models for DPP-4 is known [15-17]. Therefore, it is of interest to identify molecules to inhibit DPP-4 using molecular docking analysis.

\section{Methodology:}

Sequence to structure modeling and docking analysis of DPP-4:

The DPP-4 protein sequence downloaded from GenBank was analyzed in a comprehensive using tools such as Clustal Omega, Pfam, Prosite, SMART, PANTHER, PHYLIP, STRING and InterProScan, molecular docking and ligand-protein analysis tools to glean valuable insights [11-22].

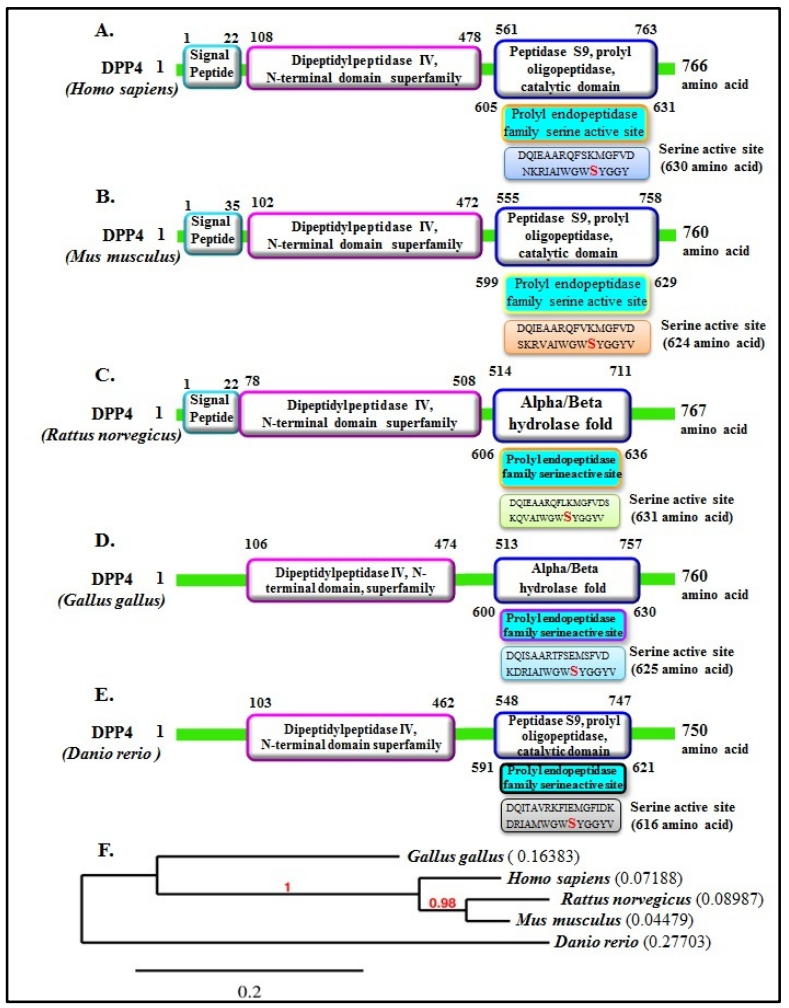

Figure 2: Domain and phylogeny analysis of DDP-4 in different organisms. 


\section{BIOINFORMATION \\ Discovery at the interface of physical and biological sciences}

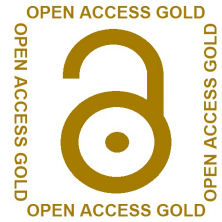

\section{A.}

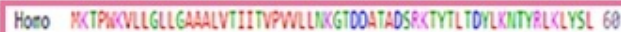

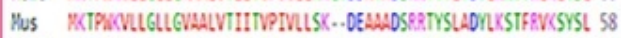

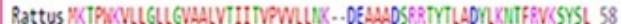

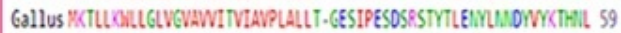

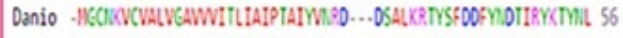

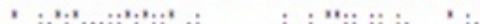

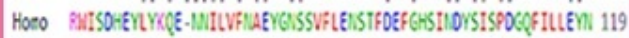

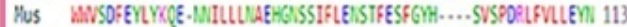

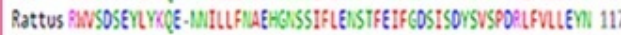

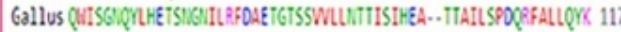

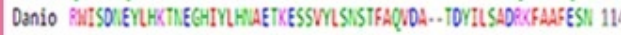

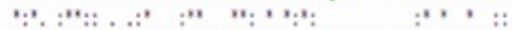

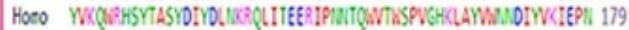

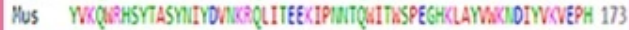

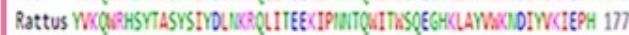

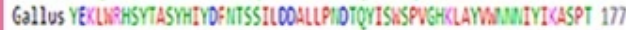

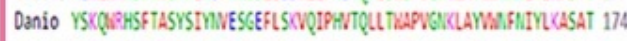

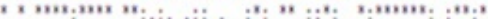

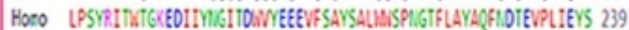

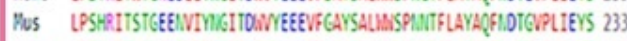

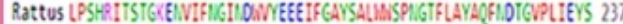

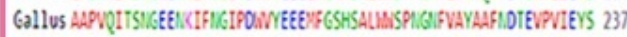

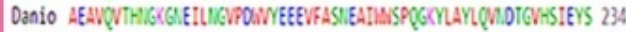

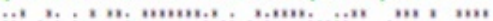

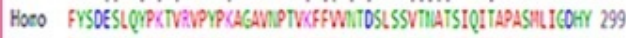
hus FYSOESLOVPSTWIPVPCAGAMPTWCFFTVIDSLSSSSSAAPIOIPAPASVAPCOHY 293

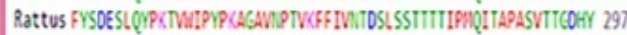

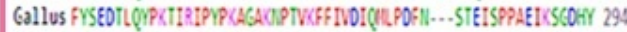

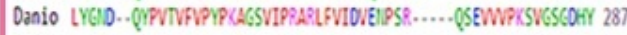

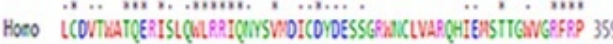

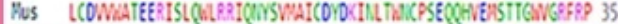

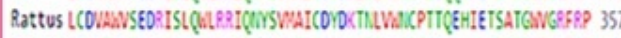

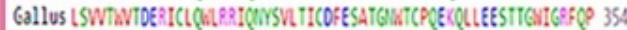

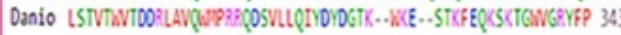

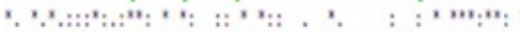

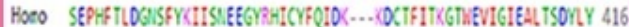

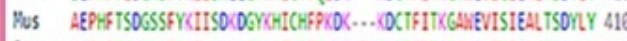

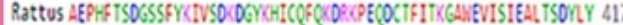

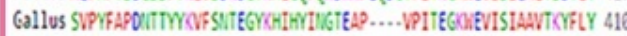

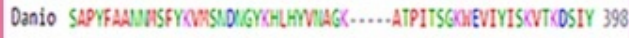
n..... .............. \#, . . . . . .

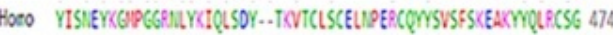

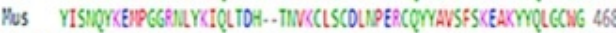

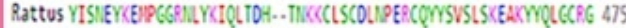

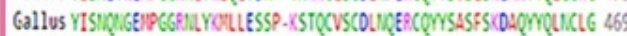
Danio WSIENAPPGPPILYKISISSSGHSAPKCLTCALYEDPCQNSSAYFSLIASYFPIDCYG 458

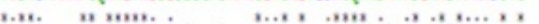

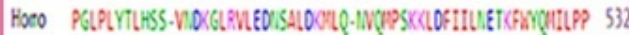

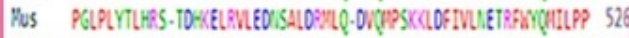

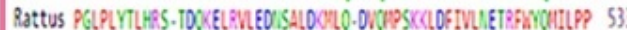

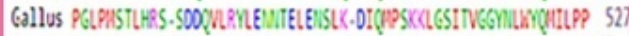

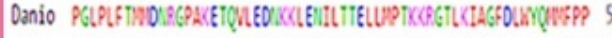

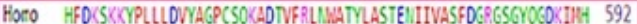

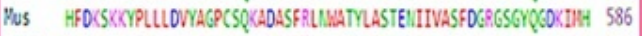

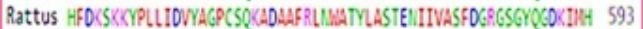

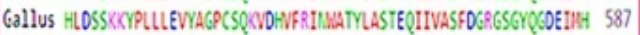

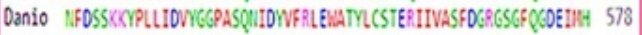

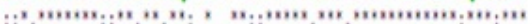

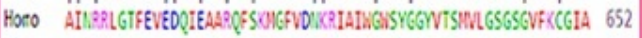

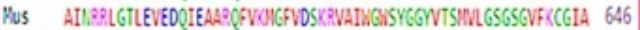

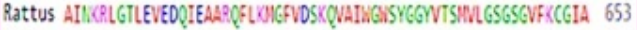

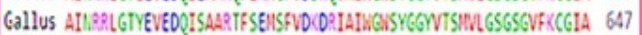

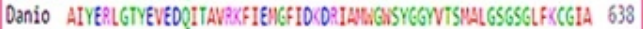

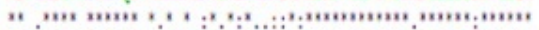

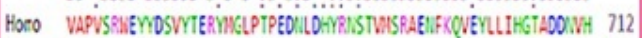

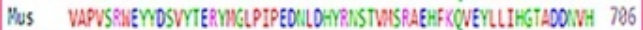

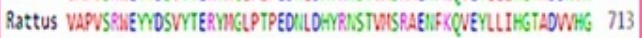

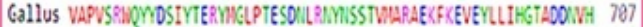

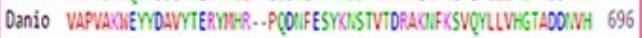

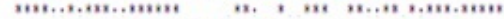

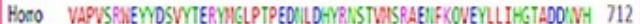

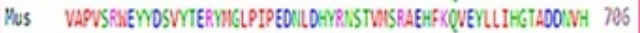

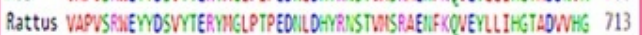

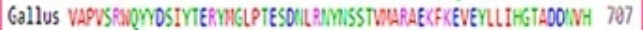

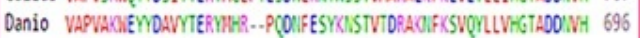

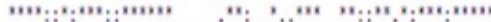

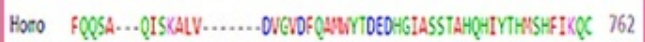

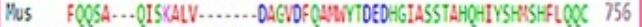

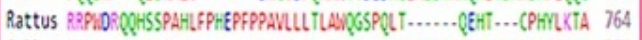

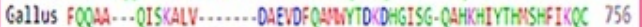

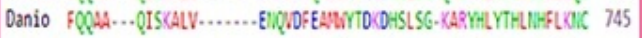
$::^{*},: \quad: * \quad *::$. Nus FSLH. 760 Rattus LLP.. 767 Gallus FSLP. $\quad 760$ Danio FaECK 750

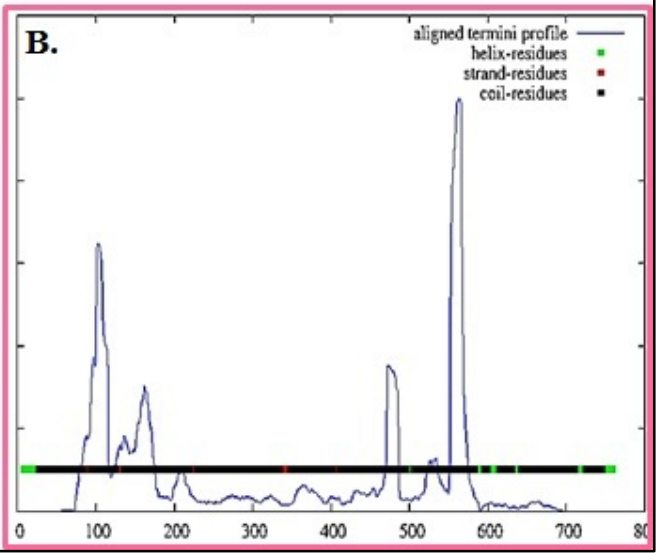

Figure 1: (A) MSA of DDP-4 from different organisms (Homo sapiens, Rattus norvegicus, Mus musculus, Danio rerio and Gallus gallus) (B) Secondary structure information on DDP-4 


\section{BIOINFORMATION \\ Discovery at the interface of physical and biological sciences}
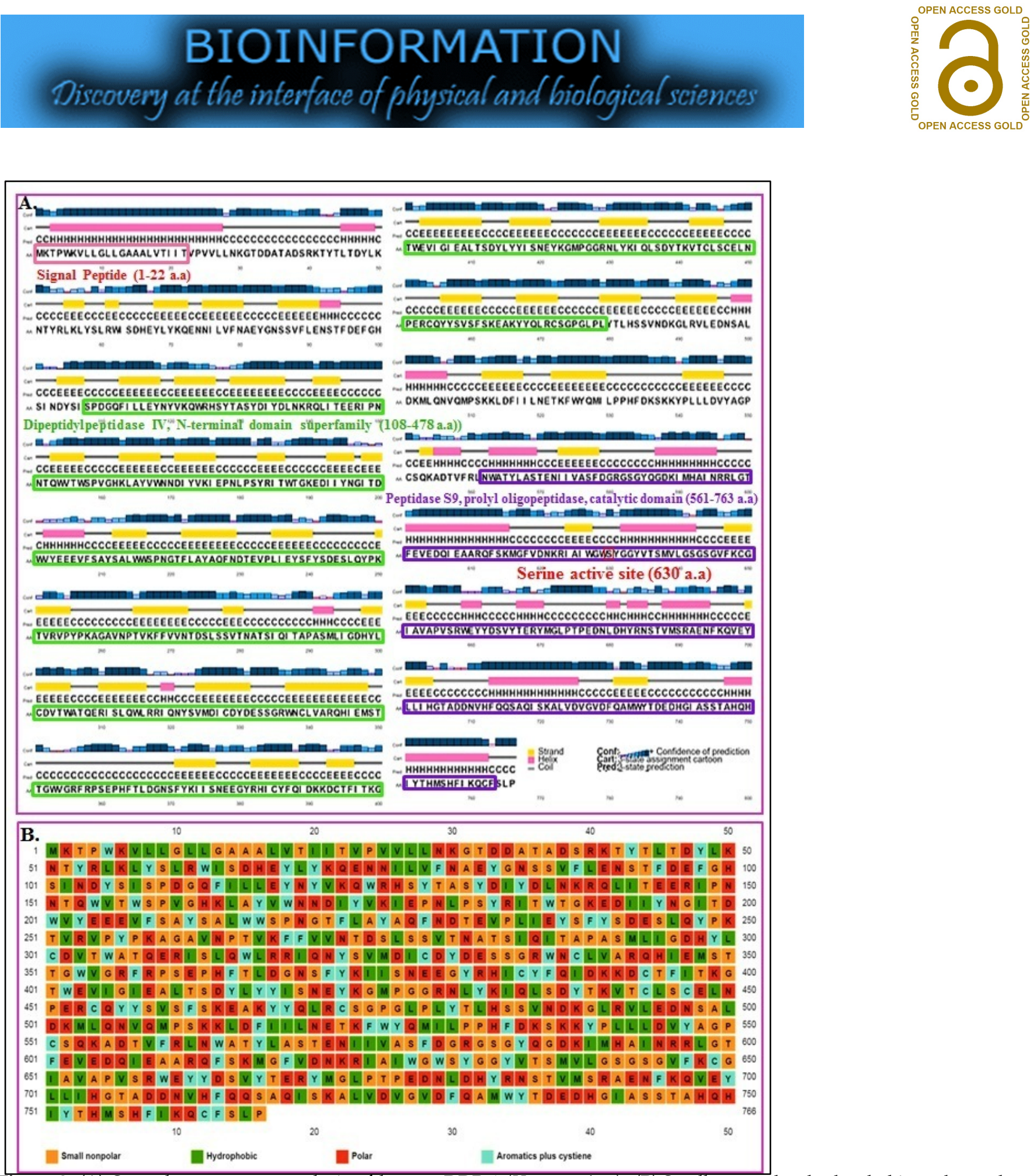

Figure 3: (A) Secondary structure analysis of human DDP-4 (Homo sapiens). (B) Small non-polar, hydrophobic, polar and aromatic plus cysteine residues in human DDP-4. 


\section{BIOINFORMATION}

Discovery at the interface of physical and biological sciences

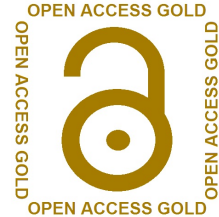

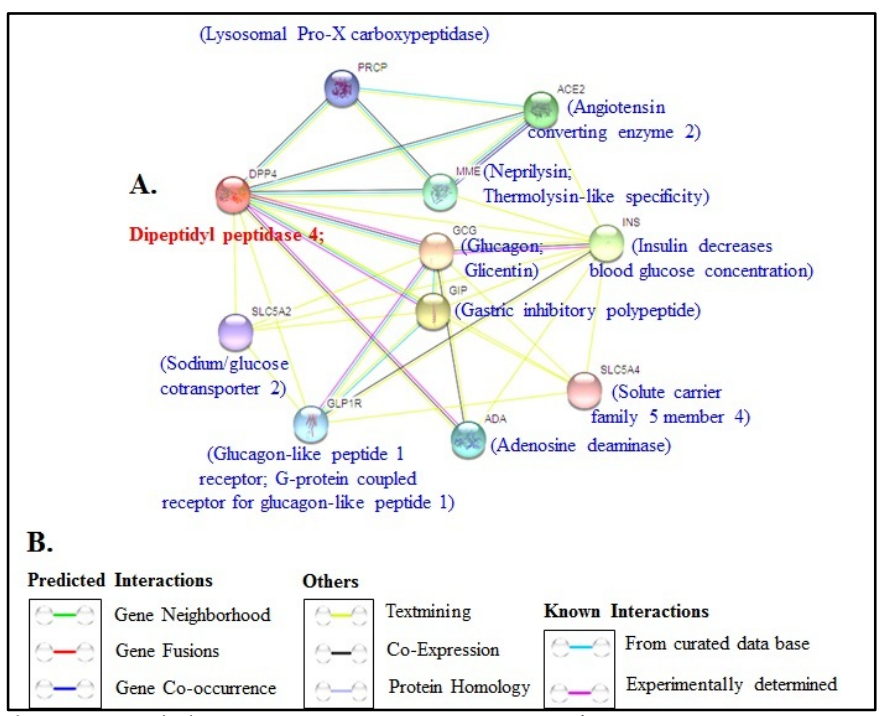

Figure 4: (A) Interacting proteins with DPP4 using STRING v10.database. (B) Explanation of interactions shown.

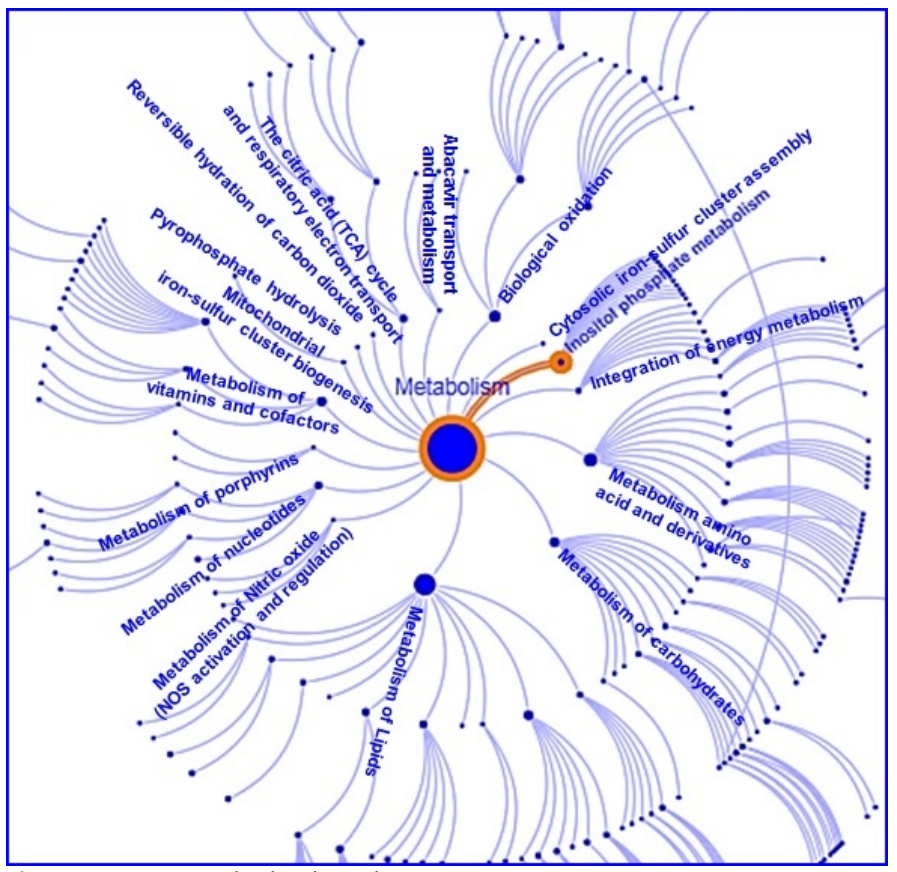

Figure 5: DDP-4 linked pathways.
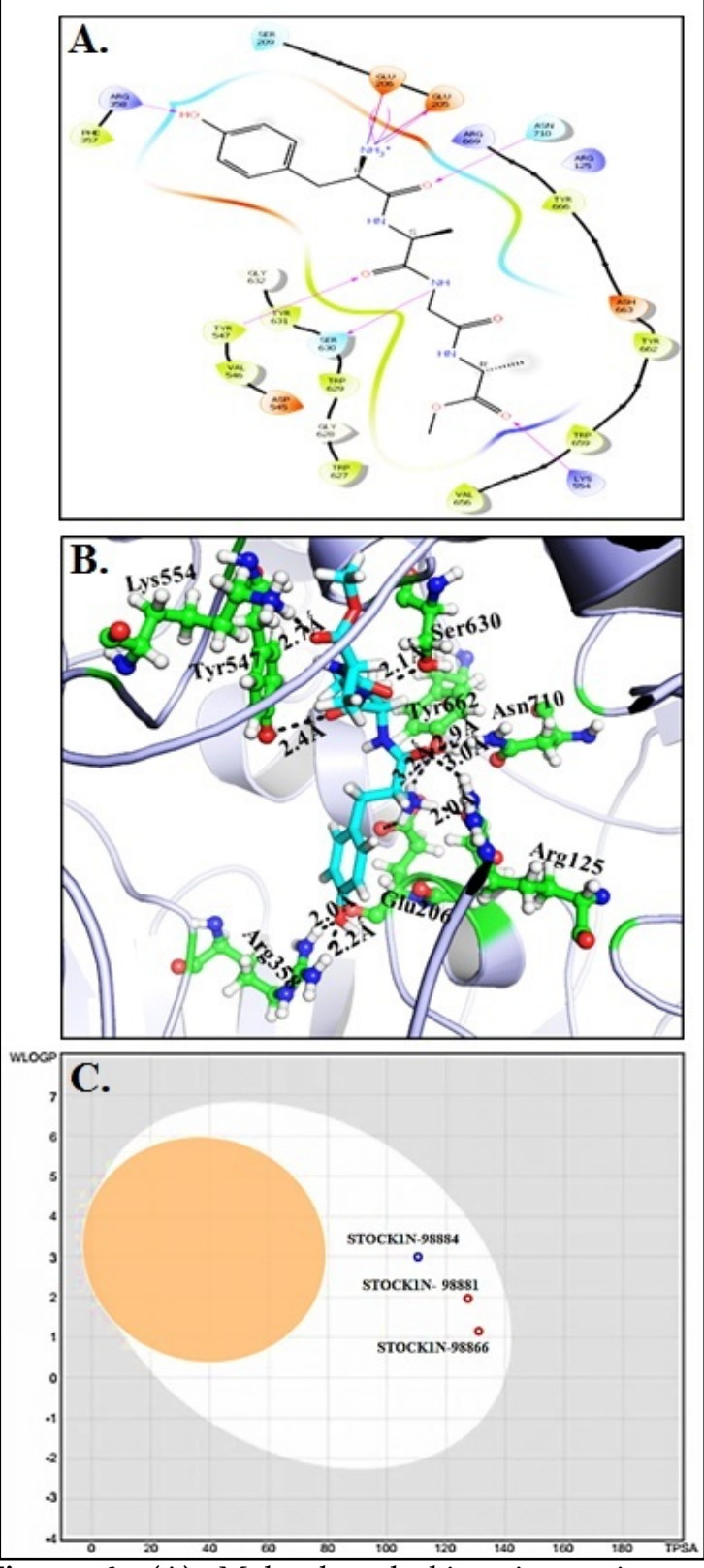

Figure 6: (A) Molecular docking interaction of DPP4 with STOCK1N-98884. (B) Cartoon interpretation of DPP4 with compound STOCK1N-98884. (C) Boiled-egg plot.

Table 1: Lowest binding energy for the Ligands-Protein interaction, along with scores for various interaction types, as detected by GLIDE 


\section{BIOINFORMATION \\ Discovery at the interface of physical and biological lsciencess}

GScore; Glide extra precision scores (kcal/mol) Lipophilic E Vdw; Chemscore lipophilic pair term and fraction of the total protein-ligand vdw energy

HBond; Hydrogen-bonding term

\begin{tabular}{lrrrrrl} 
Compounds ID & \multicolumn{1}{l}{ Binding Energy } & GScore & Lipophilic E vdw & H-bond & Electro & Protein ligands interaction \\
\cline { 2 - 2 } & MM-GBSA (kcal/mol) & & & & \\
STOCK1N-98884 & -72.7837 & -11.56 & -2.91 & -6.87 & -2.01 & Glu:205, Glu:206, Try :547, Ser:630 and Asn710 \\
STOCK1N-98881 & -61.2792 & -10.2 & -3.37 & -4.44 & -2.41 & Arg:125, Glu:205, Glu:206, Lys:554, Trp:629 and Ser:630 \\
STOCK1N-98866 & -59.2571 & -9.58 & -2.46 & -3.65 & -3.19 & Arg:125, Try :547, Lys:554 and Trp:629 \\
$\begin{array}{l}\text { Known Inhibitor } \\
\text { Linagliptin }\end{array}$ & -44.1282 & -6.79 & -2.22 & -2.61 & -0.34 & Try :547, Ser:630 and Asn710 \\
\hline
\end{tabular}

Electro; Electrostatic rewards Protein ligands interaction; p-p stacking, p-cat interaction and hydrogen bond between the ligands and protein

Table 2: Evaluation of drug-like properties of the lead molecules by Qikprop Maestro 10.5 molecular docking suite

\begin{tabular}{|c|c|c|c|c|c|c|}
\hline Molecule & $\begin{array}{l}\text { QPlog Po/w } \\
(-2.0 \text { to } 6.5)\end{array}$ & $\begin{array}{l}\text { Q P log } \\
\text { HERG } \\
\text { (acceptable } \\
\text { ange: } \\
\text { above -5.0) }\end{array}$ & $\begin{array}{l}\text { QPP Caco } \\
(\mathrm{nm} / \mathrm{s}) \\
<25-\text { poor } \\
>500-\text { great }\end{array}$ & $\begin{array}{l}\text { Q P log, } \\
\text { BB } \\
(-3 \text { to } 1.2)\end{array}$ & $\begin{array}{l}\text { QPP } \\
\text { MDCK } \\
(\mathrm{nm} / \mathrm{s})\end{array}$ & $\begin{array}{l}\text { Q Plog } \\
\text { Kp } \\
(-8.0 \text { to - } \\
0.1)\end{array}$ \\
\hline STOCK1N-98884 & -0.30 & -1.056 & 131.328 & -0.94 & 70.119 & -2.798 \\
\hline STOCK1N-98881 & 3.376 & -0.015 & 283.926 & -0.628 & 485.3 & -2.406 \\
\hline STOCK1N-98866 & 2.219 & -3.804 & 143.431 & -1.641 & 60.643 & -3.179 \\
\hline
\end{tabular}

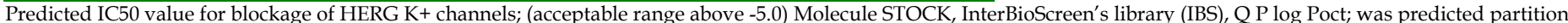

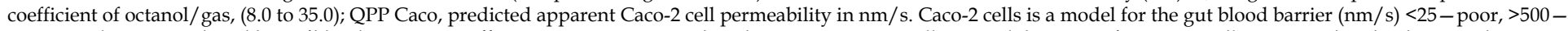

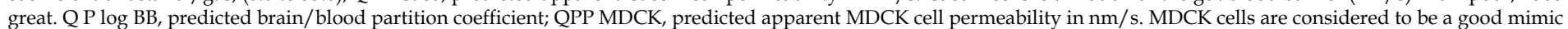

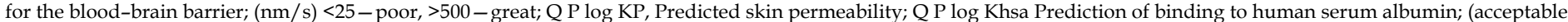
range -1.5 to 1.5 )

Table 3: Boiled egg parameters

\begin{tabular}{lllllll}
\hline Molecule & MW & TPSA & XLOGP3 & MLOGP & GI absorption & BBB permeant \\
\hline STOCK1N-98884 & 430.88 & 159.85 & -0.30 & -0.66 & High & No \\
STOCK1N-98881 & 624.04 & 158.30 & 2.99 & 0.23 & Low & No \\
STOCK1N-98866 & 421.40 & 127.08 & 2.81 & 0.93 & High & No \\
\hline
\end{tabular}

Table 4: Biological activity spectrum of compounds (Pa - Active; $\mathrm{Pi}$ - Inactive)

\begin{tabular}{llll}
\hline Molecule & $\mathrm{Pa}$ & $\mathrm{Pi}$ & Activity \\
\hline STOCK1N-98884 & 1.219 & 0.449 & Anti-diabetic \\
STOCK1N-98881 & 1.812 & 0.642 & Anti-diabetic \\
STOCK1N-98866 & 1.121 & 0.318 & Anti-diabetic \\
\hline
\end{tabular}

\section{Results \& Discussion:}

A comprehensive analysis of DDP-4 using sequence and structure information is highly relevant in the fight against T2DM with reference to known data in the literature. The Multiple Sequence Analysis (MSA) of DDP-4 from different organisms such as Homo sapiens (DPP4, 766 amino acid), Rattus norvegicus (DPP4, 767 amino acid), Mus musculus (DPP4, 760 amino acid), Danio rerio (DPP4, 750 amino acid) and Gallus gallus (DPP4, 760 amino acid) is given in Figure 1. Secondary structure information of DDP-4 is also shown in Figure 1. Domain and phylogeny analysis of DDP-4 in different organisms is given in Figure 2. The Secondary structure analysis of human DDP-4 along with small nonpolar, hydrophobic, polar, and aromatic plus cysteine residues in human DDP-4 is shown in Figure 3. Protein-protein interaction network linked to DDP-4 is shown in Figure 4. We further show the DDP-4 associated pathways in Figure 5. The molecular docking interaction of DPP4 with STOCK1N-98884 is given in Figure 6 and Tables 1 to 4 . This information gleaned from the analysis of DDP-4 is relevant in the design and development of novel compounds in combating the disease.

\section{Conclusion:}

We document compounds STOCK1N-98884, STOCK1N-98881, and STOCK1N-98866 from the IBS ligand database with optimal binding features with DPP-4 towards combating T2DM.

\section{Conflict of interest:}

There are no conflicts of interest.

\section{Acknowledgments:}

The authors sincerely thank Almanac Life Science India Pvt. Ltd. for analysis and support. 


\section{BIOINFORMATION \\ Discovery at the interface of physical and biological sciences}

\section{References:}

[1] Care D Diabetes Care 2019. 42: S81

[2] Nilsson E et al. Diabetes 2014 63: 2962 [PMID: 24812430]

[3] Monami M et al. Obesity and Metabolism 2013 15: 112 [PMID: 22925682]

[4] Dunkley AJ et al. Diabetes Care 2014 37: 922 [PMID: 24652723]

[5] Guido RV et al. estudos avançados 2010 24: 81

[6] Gautier J et al. Diabetes and metabolism 2005 31: 233 [PMID: 16142014]

[7] Elrishi M et al. Practical Diabetes International 2007 24: 474

[8] Bjelke JR et al. Journal of Biological Chemistry, 2004 279: 34691[PMID: 15175333]

[9] Gross JL et al. Arquivos Brasileiros de Endocrinologia and Metabologia 2002 46: 16

[10] Quevillon E et al. Nucleic acids research 2005 33: W116 [PMID: 15980438]

[11] Tarique M et al. Frontiers in microbiology 2017 8: 130 [PMID: 28232818]
[12] Castresana J Molecular biology and evolution 2000 17: 540 [PMID: 10742046]

[13] Malik A et al. Bioinformation 2020 16: 223

[14] Afaq S et al. Bioinformation 2020 16: 229

[15] Nugent T and Jones DT BMC bioinformatics 2013 14: 276 [PMID: 24047460]

[16] Anisimova M and Gascuel O Systematic biology 2006 55: 539 [PMID: 16785212]

[17] Mishra J and Bhalla US Biophysical Journal 2002 83: 1298 [PMID: 12202356]

[18] Bhardwaj SK et al. Brain research bulletin 1999 49: 155 [PMID: 10435778]

[19] Johnson TO et al.Nature Reviews Drug Discovery 2002 1: 696 [PMID: 12209150]

[20] Friesner RA et al. Journal of medicinal chemistry 2004 47: 1739 [PMID: 15027865]

[21] Tripathi SK et al. Journal of theoretical biology 2013 334: 87 [PMID: 23727278]

Edited by P Kangueane Citation: Alsamghan et al. Bioinformation 16(6): 444-451 (2020)

License statement: This is an Open Access article which permits unrestricted use, distribution, and reproduction in any medium, provided the original work is properly credited. This is distributed under the terms of the Creative Commons Attribution License

\section{Articles published in BIOINFORMATION are open for relevant post publication comments and criticisms, which will be published immediately linking to the original article for FREE of cost without open access charges. Comments should be concise, coherent and critical in less than 1000 words.}




\section{BIOINFORMATION}

Discovery at the interface of physical and biological sciences
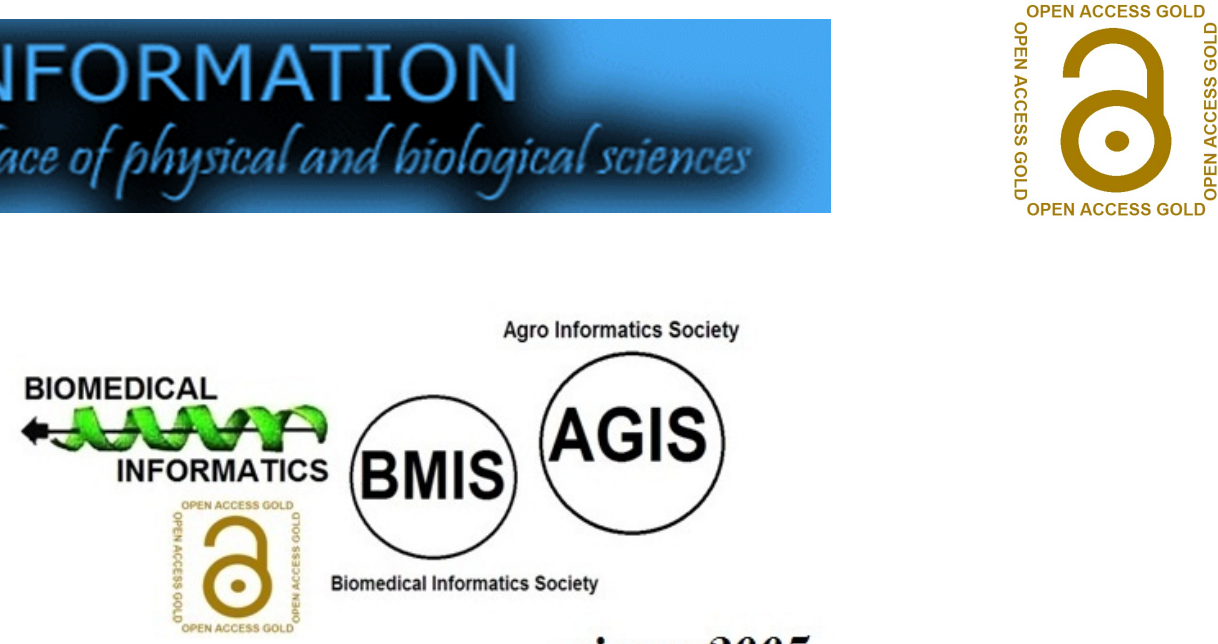

since 2005

\section{BIOINFORMATION}

Discovery at the interf ace of physical and biological sciencess

\section{indexed in}

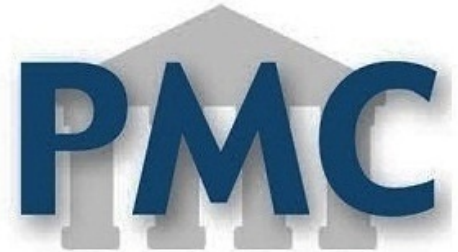

PublMed

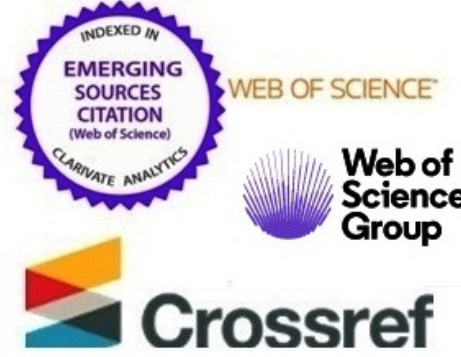

EBSCO

ResearchGate
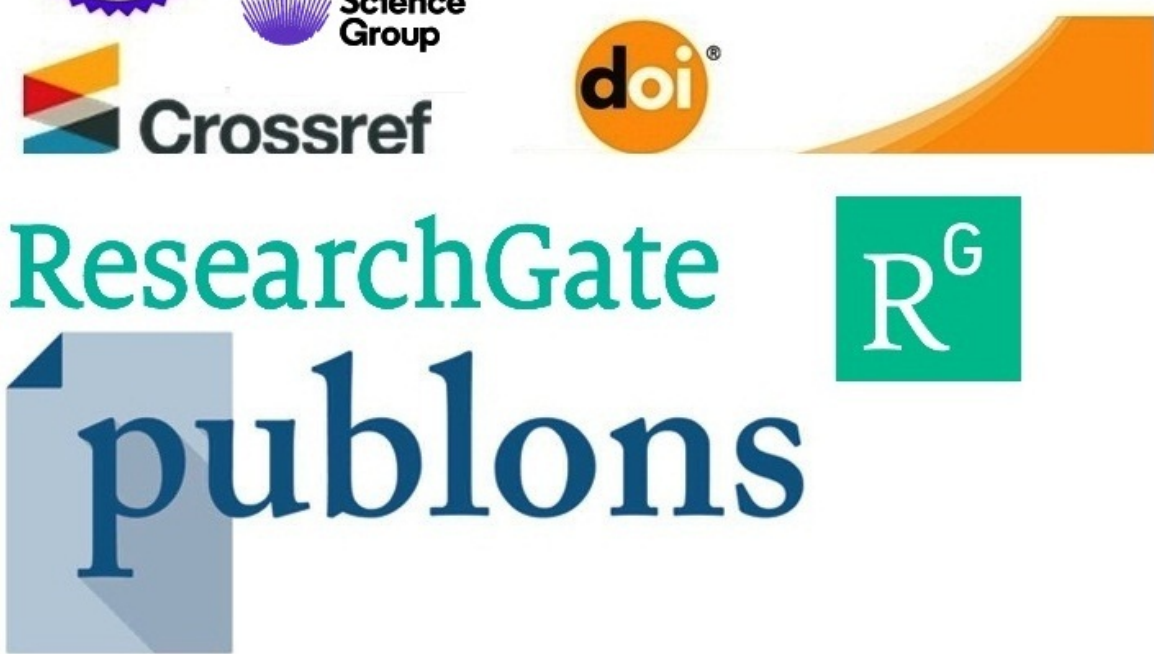